\title{
O planejamento estratégico garante a sustentabilidade ambiental urbana? Considerações sobre o Plano Fortaleza 2040.
}

Does strategic planning ensure urban environmental sustainability? Considerations about the Fortaleza 2040 Plan.

¿La planificación estratégica asegura la sostenibilidad ambiental urbana? Consideraciones sobre el Plan Fortaleza 2040.

Samuel Tavares Pinheiro Mestrando em Arquitetura, Urbanismo e Design, PPGAU+D-UFC, Brasil samuelpinheiro32@gmail.com

José Almir Farias Professor Doutor, PPGAU+D-UFC, Brasil josealmirfarias@gmail.com 


\title{
RESUMO
}

Diante das incertezas econômicas, sociais e ambientais do cenário atual globalizado, o planejamento estratégico de cidades surge como uma possibilidade de política pública para alcançar a sustentabilidade ambiental urbana. Este trabalho tece considerações sobre como o Plano Estratégico Fortaleza 2040 aborda a sustentabilidade ambiental urbana, bem como os obstáculos para alcançá-la. Este artigo se lança, portanto, no objetivo de identificar alguns dos atributos e particularidades da relação entre planejamento estratégico e sustentabilidade ambiental urbana. A metodologia adotada nesta investigação faz uso da revisão da literatura, análise documental e cartográfica, com destaque para a análise do discurso. $O$ texto que se segue está estruturado em três seções. A primeira parte versa sobre a relação entre sustentabilidade ambiental urbana e planejamento estratégico na gestão das cidades. A segunda seção dá ênfase a uma leitura do Plano Fortaleza 2040, destacando-se as suas proposições no campo da sustentabilidade ambiental urbana. A última seção é dedicada a questões que se reportam aos obstáculos enfrentados pelo planejamento estratégico para atingir os objetivos de sustentabilidade ambiental urbana.

PALAVRAS-CHAVE: Planejamento Estratégico. Sustentabilidade Ambiental Urbana. Plano Fortaleza 2040.

\begin{abstract}
Given the economic, social and environmental uncertainties of the current globalized scenario, strategic city planning emerges as a public policy possibility to achieve urban environmental sustainability. This paper presents considerations on how the Fortaleza 2040 Strategic Plan addresses urban environmental sustainability, as well as the obstacles to achieving it. This article, therefore, aims to identify some of the attributes and particularities of the relationship between strategic planning and urban environmental sustainability. The methodology adopted in this research makes use of literature review, documentary and cartographic analysis, with emphasis on discourse analysis. The following text is structured in three sections. The first part deals with the relationship between urban environmental sustainability and strategic planning in city management. The second section emphasizes a reading of the Fortaleza Plan 2040, highlighting its propositions in the field of urban environmental sustainability. The last section is dedicated to issues that address the obstacles faced by strategic planning to achieve urban environmental sustainability goals.
\end{abstract}

KEYWORDS: Strategic Urban Planning. Environmental Sustainability. Fortaleza 2040 Plan.

\section{RESUMEN}

Ante las incertidumbres económicas, sociales y ambientales del escenario actual globalizado, la planificación estratégica de ciudades surge como una posibilidad de política pública para alcanzar la sustentabilidad ambiental urbana. Este trabajo tensa consideraciones sobre cómo el Plan Estratégico Fortaleza 2040 aborda la sustentabilidad ambiental urbana, asi como los obstáculos para alcanzarla. Este artículo se lanza, por lo tanto, en el objetivo de identificar algunos de los atributos y particularidades de la relación entre planificación estratégica y sustentabilidad ambiental urbana. La metodología adoptada en esta investigación hace uso de la revisión de la literatura, análisis documental y cartográfico, con destaque para el análisis del discurso. El texto siguiente está estructurado en tres secciones. La primera parte versa sobre la relación entre sostenibilidad ambiental urbana y planificación estratégica en la gestión de las ciudades. La segunda sección da énfasis a una lectura del Plan Fortaleza 2040, destacándose sus proposiciones en el campo de la sustentabilidad ambiental urbana. La última sección está dedicada a cuestiones que se refieren a los obstáculos enfrentados por la planificación estratégica para alcanzar los objetivos de sustentabilidad ambiental urbana.

PALABRAS-CLAVE: Planificación Estratégica. Sostenibilidad Ambiental Urbana. Plan Fortaleza 2040. 



desenvolvimento integrando questões econômicas e ambientais em maior escala. As instituições neoliberais ao incorporar o discurso ambiental e o conteúdo crítico direcionado às contradições socioambientais trazidas pelo desenvolvimento econômico, o transformaram em ideologia na dispersão de conceitos que gravitam em torno da sustentabilidade (VEIGA, 2010; RIBEIRO, 2012).

\section{PLANO FORTALEZA 2040: NOVOS CAMINHOS PARA UMA CIDADE (IN)SUSTENTÁVEL?}

Em qualquer lugar do mundo, planejar o crescimento e o desenvolvimento de uma cidade com quase 3 milhões de habitantes não é tarefa simples. No caso de Fortaleza soma-se a esta dificuldade o fato de ser uma típica metrópole brasileira com tudo que tal denominação traz de contradições, injustiças, deficiências, conflitos e potencialidades. Entre 2014 e 1016, o governo municipal se lança no desafio de elaborar o Plano Fortaleza $2040^{2}$, um ambicioso portfólio de estirpe estratégica, com o objetivo maior de oferecer alguma coerência ao conjunto de planos e normas setoriais, e assim poder configurar uma visão futura da cidade.

Busca-se nessa sessão apresentar uma rápida síntese da estrutura geral e dos procedimentos metodológicos do Plano Fortaleza 2040, de modo a extrair os principais elementos que indicam o seu compromisso com a sustentabilidade ambiental urbana. Para esta análise enfoca-se, particularmente, o eixo estratégico de meio ambiente. De início, é preciso reconhecer o amplo empenho de sistematização realizado pelas equipes técnicas, tendo em vista a amplitude do escopo do Plano. Reconhece-se também um esforço no sentido de mobilizar e articular os diferentes atores sociais e agentes públicos em torno das "grandes prioridades de desenvolvimento". Admite-se, também, que as considerações explicitadas a seguir são ainda preliminares, uma vez que um evento recente como este não oferece o distanciamento temporal necessário para uma análise de maior profundidade.

O Plano Fortaleza 2040 é um típico produto do modelo de planejamento estratégico urbano, ainda em que sua versão mais contemporânea que busca "resolver" as críticas aos documentos da primeira geração. Com o slogan "Construindo a Fortaleza que Queremos", sua aspiração maior é transformar a capital cearense em uma cidade mais acessível, justa e acolhedora,

\footnotetext{
${ }^{2}$ O Plano Fortaleza 2040 é coordenado pelo Instituto de Planejamento de Fortaleza (Iplanfor), com a execução técnica da Fundação Cearense de Pesquisa e Cultura (FCPC/UFC), por meio da qual foram contratados vários especialistas e consultores. Este plano encontra-se publicado em 8 volumes assim distribuídos: Vol.1 Plano Fortaleza 2040; Vol.2 Equidade Social, Territorial e Econômica; Vol. 3 Cidade Conectada, Acessível e Justa; Vol. 4 Vida Comunitária, Acolhimento e Bem-Estar; Vol. 5 Desenvolvimento da Cultura e do Conhecimento; Vol. 6 Qualidade do Meio Ambiente e dos Recursos Naturais; Vol. 7 Dinamização Econômica e Inclusão Produtiva; Vol. 8 Governança Municipal, Modelo de Gestão e Participação da Sociedade. Disponível em http://observatoriodefortaleza.fortaleza.ce.gov.br/downloads.
} 

holístico, predomina uma visão estática e isolacionista da política ambiental, observável na frágil análise de integração e transversalidade com as demais políticas urbanas. Não há um esforço para concatenar soluções consistentes e toda a discussão gira em torno da compreensão do contexto ambiental em termos de metas, que dependem do alcance das mudanças no padrão de crescimento econômico, o que inclui inovação tecnológica, o fortalecimento das instituições públicas e o aumento da disponibilidade de recursos públicos (metas fiscais).

O Plano Fortaleza 2040 emerge, portanto, como um compilado do receituário que vem se consagrando alhures, e expõe o papel secundário da sustentabilidade urbana como um mote para os planos setoriais. $\mathrm{O}$ discurso de desenvolvimento sustentável se mostra convincente na enumeração dos problemas ambientais, muito embora não trate das contradições inerentes à realidade local. Não há novidades nem ousadia propositiva, já que as recomendações são derivadas de estudos pré-existentes (nacionais ou internacionais) ou em metas ${ }^{5}$ de difícil alcance se consideradas em modo estanque e desagregado. A orientação de estabelecer novos marcos regulatórios para a política ambiental parece responder com o "mais do mesmo": criação de uma Secretaria Municipal do Meio Ambiente; alinhamento das demais leis da política urbana, etc.

Considerando o desafio de planejar o desenvolvimento urbano em um período de longo prazo (25 anos), o Plano Fortaleza 2040 atesta a necessidade de se fortalecer as políticas e legislações (municipais e federais), afim de atrair investimentos para se alcançar os objetivos propostos. Depreende-se deste posicionamento, uma concordância com aquilo que diz Ascerald (1999) a respeito do uso da política ambiental para inserir a cidade numa lógica de atenção às exigências estabelecidas pelas agências internacionais, em prol de interesses econômicos não necessariamente relacionados aos seus desafios locais mais urgentes.

\section{UM POSSÍVEL ROTEIRO PARA UMA CRÍTICA DE SEGUNDO GRAU.}

A leitura do Plano Fortaleza 2040 permitiu alinhavar alguns questionamentos sobre a relação entre planejamento estratégico e sustentabilidade ambiental urbana. Em realidade, trata-se de comentários prático-teóricos sobre os obstáculos inerentes a este arranjo, cujas respostas aos problemas urbanos não termina no modelo em si nem nas realizações que ele inspira. Esta análise encontra-se estruturada em três sucintos tópicos descritos a seguir.

\subsection{A "visão de futuro" e a "cidade-modelo".}

\footnotetext{
${ }^{5}$ O Plano Fortaleza 2040 tem como metas: a ampliação da reciclagem de resíduos recicláveis dos percentuais atuais $2 \%$ para mínimo de $51 \%$ em 2040; redução a zero a emissão de gases de efeito estufa até 2040; ampliação da geração distribuída de energia elétrica solar com base em sistemas fotovoltaicos (micro e minigeração) de modo a alcançar 10 mil GWh/ano até 2040.
} 
Duas expressões ganham destaque no discurso do Plano Fortaleza 2040: "visão de futuro" e "cidade-modelo". Com a ideia que todas as decisões de longo prazo devem ser apoiadas em um consenso de como as coisas deverão se comportar no tempo futuro, o Plano Fortaleza 2040 apoia-se em métodos do marketing empresarial para pensar uma "cidade do amanhã". Evidencia-se a adoção de uma escala linear de tempo, partindo do passado, percorrendo o presente e almejando um futuro de cidade construído de modo consensual. Grosso modo, a visão de futuro é tributária de uma teoria temporal do tempo, mas não realiza necessariamente um percurso cronológico e sistemático.

A visão do futuro, como se sabe, é uma promessa do amanhã, uma nostalgia do que virá, e se encontra muito próxima da ideia de progresso contínuo. Mas é preciso estar atento, pois a nostalgia sozinha leva, na melhor das hipóteses, ao impasse reacionário, e na pior, a todas as formas de fascismo. O futuro sozinho, sem nostalgia, leva, na melhor das hipóteses, ao culto de um progresso cego, e na pior às aberrações da tábula rasa (BORNARD e GAUJARD, 2016). A visão de futuro do Plano Fortaleza 2040 se orienta por "cenários alternativos", mas curiosamente se faz em um discurso uníssono (sem polifonia) do presente para justificar suas proposições. Deste modo, a gestão pública apoia-se em métodos para estabilizar, convencer e formalizar sua projeção de futuro, reforçando com este intuito os modelos mentais pouco conscientes.

Figura 2: Visões de Futuro: Planos de Massa para a Oficina do Urubu (esquerda) e Estação Metrofor Sul (direita).
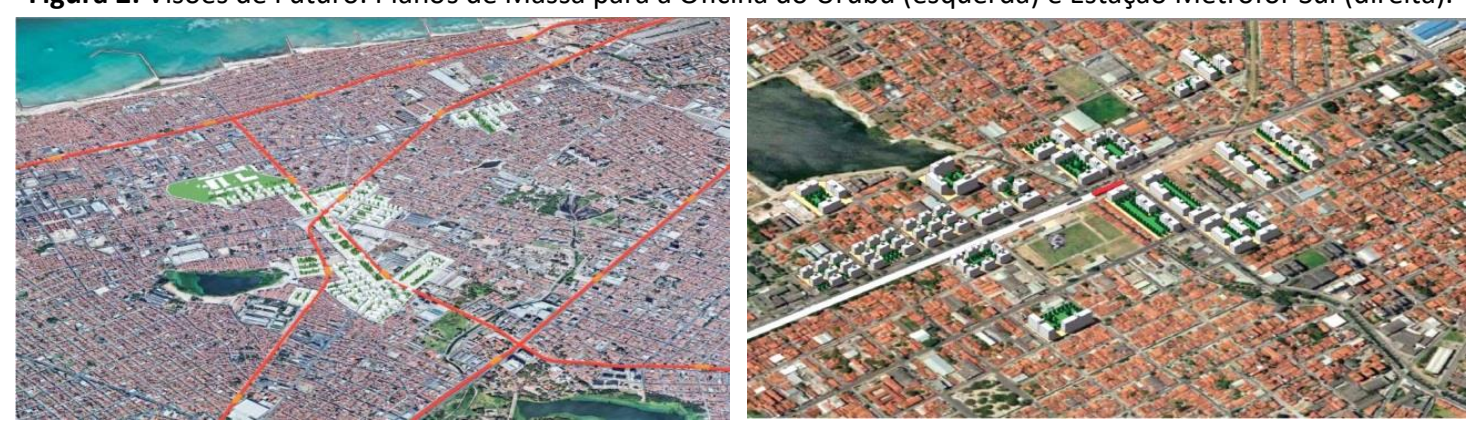

Fonte: Plano Fortaleza 2040 (2016).

A noção de "cidade-modelo" foi amplamente incorporada pelo planejamento estratégico, como uma imagem de marca construída pela ação combinada de governos locais, atores hegemônicos com interesses localizados, agências multilaterais e redes de cidades. A referência principal desta noção de cidade-modelo é a cidade de Curitiba sobre a qual se difundiu o slogan da "cidade que deu certo, por que planejou". Segundo Sánchez (2001, p.31), há suficientes indicadores da existência de uma rede global onde operam fluxos informacionais ligados a representações de uma urbanidade-modelo descolada e imposta à urbanidade social complexa. Nessa esfera da circulação simbólica, discursos, imagens e políticas de city marketing acompanham e alimentam processos de reestruturação produtiva e de atração de capitais internacionais. 
A proposta de transformar Fortaleza em uma cidade-modelo pode ser encarada, por antinomia, como uma estratégia de escamotear as dificuldades relativas ao enfrentamento das desigualdades urbanas atuais. Algumas destas características negativas estão evidenciadas no próprio diagnóstico do Plano, que destaca problemas como a ocorrência de ocupações de risco, déficits habitacionais e ausência de saneamento básico. Entretanto, para se lançar no mercado mundial e atrair novos fluxos de investimentos, a cidade precisa justapor a tudo isso uma imagem positiva que se efetiva principalmente através do estímulo ao empreendedorismo das grandes intervenções.

\subsection{Governança e Legitimidade Social.}

O conceito de governança foi introduzido no início dos anos 90 por organizações internacionais (ONU, Banco Mundial, FMI) para fazer da ação governamental um assunto de debate. A "boa governança" foi definida em termos de seleção e capacidade dos gestores públicos de tomar decisões regulatórias, bem como da legitimidade dos arranjos governamentais. O Plano Fortaleza 2040 tem na noção de governança um dos seus pilares ao adotar a estratégia de criação do Sistema de Governança Municipal ${ }^{6}$. Trata-se de um conjunto de instrumentos públicos com a função de garantir a participação cidadã e o controle social efetivo nas decisões sobre a cidade propostas no plano. Depreende-se, portanto, que a participação da sociedade civil é fundamental para a consecução dos objetivos do Plano, resultando disso o distintivo da boa governança.

Todavia, é possível argumentar que a participação democrática no planejamento estratégico busca concretamente a legitimação, em detrimento da legitimidade. A literatura político-jurídica faz a seguinte distinção entre legitimidade e legitimação: a primeira busca o consenso, enquanto a segunda visa ao cumprimento do direito (MACHADO et al, 2011). Dito de outro modo, o Plano Fortaleza 2040, como instrumento da política urbana, tem o interesse precípuo de assegurar ao poder municipal o direito legal de efetivar as ações propostas, embora necessite sempre de legitimidade social para executá-las.

Do mesmo modo como ocorre no ambiente empresarial, para atingir a legitimidade social, os gestores públicos precisam adotar certos procedimentos, não porque acreditam na eficiência deles, mas porque a sociedade entende que tais mecanismos são eficazes e, por isso, impõeIhes o dever de observá-los. É por isso que a questão da participação cidadã e dos mecanismos políticos que possibilitam a inserção da sociedade na tomada de decisões políticas estão presentes na prática de planejamento estratégico e podem ser apontadas com medidas para garantir sua legitimidade.

Pode-se deduzir que o Plano Fortaleza 2040 tem seu foco essencialmente na legitimação, isto é, na busca de institucionalização da visão de futuro e do modelo de cidade. Por maior que seja

\footnotetext{
${ }^{6}$ Este dispositivo articula-se com a criação do Escritório de Gestão de Projetos e Núcleos de Gestão de Projetos, bem como do Observatório da Cidade, visando assegurar a efetiva implementação do Plano com o comprometimento da população.
} 

Fortaleza 2040. Talvez isso ocorra porque a questão ambiental, tal como está posta, parece ir de encontro a uma utopia mercadológica de cidade ideal sustentável. A sustentabilidade ambiental urbana não pode ser considerada como um estado fixo, harmonioso, mas ao contrário, trata-se de um processo dinâmico, em uma evolução não linear que demanda constante posicionamento crítico e revisão dos instrumentos de controle. A sustentabilidade ambiental urbana não possui um fim tangível, pois está vinculada a ações que buscam a equidade, a ética e a democracia, sem o comprometimento das condições ecológicas essenciais à manutenção da vida, em todas as suas formas.

\section{REFERÊNCIAS}

ACSELRAD, Henri. Discurso da Sustentabilidade Urbana. Revista Brasileira de Estudos Urbanos e Regionais. ANPUR. № 1, maio, p.79-90, 1999.

ACSELRAD, Henri (org.) A duração das cidades: sustentabilidade e risco nas políticas urbanas. Rio de Janeiro: DP\&A, 2001, p.27-56.

BORNARD, Fabienne et GAUJARD, Chrystelle. Imaginer des scénarios pour donner du sens à sa vision du futur. In Cairn. Info, v.3, $n^{\circ}$ 30, 2016, p.7-16.

CASTELLS, Manuel e BORJA, Jordi. Planes Estrategicos y Proyectos Metropolitanos. Cadernos IPPUR. Vol. XI, Jan/Dez, p.207-231, 1997.

CAVALCANTI, Clóvis. (org.). Desenvolvimento e Natureza: estudos para uma sociedade sustentável. São Paulo: Cortez, 2003.

FALCOSKI, Luiz A.N.; BRUNA, Gilda C. Plano estratégico, sustentabilidade e indicadores de desempenho urbano: novos paradigmas. In Anais da ANTAC, Maceió-AL, 2014. Disponível em http://www.infohab.org.br/entac2014/2000/Artigos/ENTAC2000_421.pdf. Acesso 27/05/2018.

FORTALEZA, Prefeitura Municipal. Plano Fortaleza 2040. 8 Volumes. Fortaleza: Iplanfor, 2016.

HARVEY, David. O neoliberalismo. História e implicações. São Paulo: Ed. Loyola, 2008.

KAUFMAN, Jerome; JACOBS, Harvey. A public planning perspective on strategic planning. In Journal of the American Planning Association, v. 53, p. 23 -33, 1987.

MACHADO, M.R.; MACHADO, M.A.V. e MURCIA, Fernando Dal Ri. Em busca da legitimidade social: relação entre o impacto ambiental da atividade econômica das empresas brasileiras e os investimentos no meio ambiente. In Revista Universo Contábil, FURB, v.7, n.1, p.20-35, jan./mar., 2011.

PFEIFFER, Peter. Planejamento Estratégico Municipal no Brasil: uma nova abordagem. Brasília: ENAP, Texto para discussão, no 37, 2000.

RIBEIRO, Fernando Pinto. O paradigma ambiental na globalização neoliberal: da condição crítica ao protagonismo de mercado. In Soc. \& Nat., Uberlândia, ano 24, n.2, mai./ago. 2012, p.211-225. 
ROGERS, Richard e GUMUCHDJIAN, Philip. Cidades para um pequeno planeta. Lisboa: GG, 2001.

SACHS, Ignacy. Estratégias de transição para o século XXI: desenvolvimento e meio ambiente. São Paulo: Studio Nobel; Fundação do Desenvolvimento Administrativo, 1993.

SÁNCHEZ, Fernanda. A reinvenção das cidades para um mercado mundial. 2ª ed. Chapecó, SC: Argos, 2010.

SÁNCHEZ, Fernanda. A reinvenção das cidades na virada de século: agentes, estratégias e escalas de ação política. Rev. Sociol. Polít., Curitiba, 16, p. 31-49, jun. 2001.

VAINER, Carlos. Os liberais também fazem planejamento urbano? In: ARANTES, Otília; VAINER, Carlos; MARICATO, Ermínia. A cidade do pensamento único: desmanchando consensos. Petrópolis: Vozes, 2000, p. 105-119.

VAINER, Carlos. Pátria, empresa e mercadoria: notas sobre a estratégia discursiva do planejamento estratégico urbano. In: Anais do VIII ENANPUR. Porto Alegre: PROPUR - UFRGS, 1999.

VEIGA, José Eli da. Sustentabilidade: a legitimação de um novo valor. São Paulo: Editora SENAC São Paulo, 2010. 